\title{
Originals
}

\section{The Response of Gastric Inhibitory Polypeptide (GIP) and Insulin to Glucose in Duodenal Ulcer Patients}

\author{
K. B. Lauritsen and A. J. Moody \\ Department of Surgical Gastroenterology, Hvidovre Hospital and Novo Research Institute, Copenhagen, Denmark
}

\begin{abstract}
Summary. The response of Gastric Inhibitory Polypeptide (GIP) and insulin to a $50 \mathrm{~g}$ oral glucose tolerance test (OGTT) and an intravenous glucose infusion (IVGI), which copied the changes in plasma glucose concentrations during the OGTT, were measured in 10 patients with duodenal ulcer and in 10 healthy control subjects. The mean responses of GIP and insulin to OGTT were significantly increased in the ulcer patients. During IVGI the responses were normal. The degree of increased GIP response in the patients was positively correlated with the plasma glucose increase during the OGTT. It is postulated that the increased GIP secretion is related to a faster glucose absorption due to rapid gastric emptying in duodenal ulcer patients. No correlation was found between basal and peak gastric acid output and the GIP response in the patients. The data demonstrate that GIP secretion is not defective in duodenal ulcer patients.
\end{abstract}

Key words: GIP, insulin, incretin, duodenal ulcer, oral glucose tolerance test.

Gastric Inhibitory Polypeptide (GIP) is released from the proximal small intestine [1] in response to oral or intraduodenal loads of glucose [2,3], amino acids [4] and triglycerides [5, 6]. Administration of exogenous GIP, in amounts sufficient to increase circulating plasma GIP levels to those found after the above stimuli, inhibits histamine-stimulated acid secretion in dogs [7] and stimulates glucose induced insulin release [8].

The present study was carried out in order to measure the variation of endogenous GIP in duodenal ulcer disease and to evaluate the role of
GIP as an incretin in man. Matched oral and intravenous glucose loads were given to normal subjects and patients with duodenal ulcer. The glucose, insulin and GIP responses to the loads were measured and related to the subjects' clinical status.

\section{Material and Methods}

\section{a. Subjects}

The patients studied were 5 females and 5 males admitted to hospital because of symptoms of persistent dyspepsia. All had radiological and endoscopic evidence of duodenal ulceration. None had a family history of diabetes mellitus. Clinical data are shown in Table 1 . Mean weight was $66 \mathrm{~kg}$; three patients were 18,19 and 23 per cent below and two were 18 and 30 per cent above while the rest were within 10 per cent of their ideal body weight [9]. The control group comprised three male and 7 female healthy, normal volunteers. All were within 10 per cent of ideal body weight. None had a family history of diabetes mellitus or duodenal ulcer disease.

\section{b. Experimental Procedure}

Oral Glucose Tolerance Test (OGTT): All subjects were on a diet containing at least $250 \mathrm{~g}$ carbohydrate per day three days before the investigation. The tests began between 8:00 and 9:00 a.m. after $10 \mathrm{~h}$ of fasting and non-smoking. The subjects were supine during the tests. Fifty g of glucose was given in $200 \mathrm{ml}$ water flavoured with lemon. Blood samples were drawn from an antecubital vein 10 and 5 min before the glucose loading and $0,5,10,20$, $30,40,50,60,90,120,150$ and 180 min after loading. Samples were collected in dry tubes and tubes 
Table 1. Clinical data of ten patients with duodenal ulcer and the integrated response of gastric inhibitory polypeptide (GIP) to oral glucose, peak acid output (PAO) and basal acid output (BAO) at histamine loading

\begin{tabular}{|c|c|c|c|c|c|c|c|c|}
\hline \multirow[b]{2}{*}{ Subject } & \multirow[b]{2}{*}{$\begin{array}{l}\text { Age } \\
\text { Years }\end{array}$} & \multirow[b]{2}{*}{$\begin{array}{l}\text { Weight } \\
\mathrm{Kg}\end{array}$} & \multirow[b]{2}{*}{$\begin{array}{l}\text { Height } \\
\mathrm{cm}\end{array}$} & \multirow[b]{2}{*}{$\begin{array}{l}\text { PAO } \\
\text { meq }\end{array}$} & \multirow[b]{2}{*}{$\begin{array}{l}\mathrm{BAO} \\
\mathrm{H}^{+} / \mathrm{h}\end{array}$} & \multicolumn{3}{|c|}{ Integrated response at OGTT } \\
\hline & & & & & & $\begin{array}{l}\text { Glucose } \\
\mathrm{mmol} / 1 \times 180 \mathrm{~min}\end{array}$ & $\begin{array}{l}\text { Insulin } \\
\mathrm{mU} / \mathrm{ml} \times 180 \mathrm{~min}\end{array}$ & $\begin{array}{l}\text { GIP } \\
\mathrm{ng} / \mathrm{ml} \times 180 \mathrm{~min}\end{array}$ \\
\hline 1 & 58 & 50 & 169 & 20 & 1 & 65 & 2.25 & 17 \\
\hline 2 & 42 & 75 & 180 & 32 & 2 & 162 & 2.00 & 35 \\
\hline 3 & 21 & 67 & 170 & 51 & 14 & 215 & 4.53 & 39 \\
\hline 4 & 39 & 78 & 169 & 30 & 5 & 283 & 2.26 & 42 \\
\hline 5 & 29 & 57 & 166 & 40 & 6 & 239 & 3.08 & 49 \\
\hline 6 & 27 & 57 & 175 & 45 & 10 & 187 & 3.49 & 52 \\
\hline 7 & 42 & 61 & 157 & 29 & 6 & 351 & 5.52 & 72 \\
\hline 8 & 56 & 85 & 169 & - & - & 334 & 4.10 & 104 \\
\hline 9 & 71 & 57 & 175 & 51 & 10 & 655 & 3.05 & 106 \\
\hline 10 & 53 & 69 & 184 & 49 & 6 & 372 & 5.36 & 120 \\
\hline \multicolumn{9}{|l|}{ Control group } \\
\hline mean & 35 & 65 & 172 & - & - & 257 & 2.74 & 38 \\
\hline range & $25-47$ & $54-85$ & $161-185$ & - & - & $82-403$ & $0.84-4.87$ & $9-82$ \\
\hline
\end{tabular}

on ice containing ammonium heparin and aprotinin $(0.7 \mathrm{mg}$ and $500 \mathrm{KIE} / \mathrm{ml}$ blood respectively). Aliquots of serum and plasma were stored at $-20^{\circ} \mathrm{C}$ until assayed.

Intravenous Glucose Infusion (IVGI): Three days to one week after the oral test each subject received an intravenous glucose infusion designed to mimic the plasma glucose curve obtained during the OGTT. Fifty per cent glucose (w/v) was infused into an antecubital vein and blood samples were drawn from the contralateral vein at the same time intervals as in the OGTT. Blood glucose concentrations during the IVGI were frequently controlled by means of the Dextrostix-Eyetone system (Miles Laboratories Inc., Elkhart, Indiana [10]), and adjusted to the plasma glucose concentrations found during the OGTT by varying the infusion speed.

Gastric Secretory Function: Gastric acid secretion was measured in all patients except one [11]. Basal acid output (BAO) and peak acid output (PAO) were expressed as milliequivalents of free acid in the first hour prior to the stimulation and in the peak 30 -min secretory response.

\section{c. Laboratory Analysis}

Plasma glucose concentrations were determined by the glucose oxidase method on a Beckman glucose analyser. Serum insulin concentrations were measured in duplicate. The insulin antiserum used bound proinsulin and insulin with equimolar potency. Tracer, ${ }^{125}$ I-labelled porcine insulin and standard, human monocomponent insulin, were obtained from the Novo Research Institute, Denmark. Separation was performed with charcoal; a separation blank without antibody was used to adjust the results. The assay working range was 3-200 $\mu \mathrm{U} / \mathrm{ml}$; detection limit was $2 \mu \mathrm{U} / \mathrm{ml}$. Between assay reproducibility was tested during 11 assays covering a period of four months. $1 \mathrm{SD}$ was $3.7 \mu \mathrm{U} / \mathrm{ml}$ at $52 \mu \mathrm{U} / \mathrm{ml}$ and $1.8 \mu \mathrm{U} / \mathrm{ml}$ at $7 \mu \mathrm{U} / \mathrm{ml}$. Measurements of insulin in sera with added insulin and in dilutions of sera yielded results which deviated less than five per cent from the expected values. Immunoreactive GIP was measured by the method of Moody and Lauritsen [12]. Anti-GIP sera were raised in five rabbits against crude GIP prepared from $20 \%$ PCCK kindly donated by V. Mutt, Stockholm. One rabbit, R 65, yielded an antiserum with sufficient sensitivity and specificity for use in an assay for plasma GIP. Freeze-dried standards containing $100 \mathrm{ng}$ GIP per vial were prepared from purified porcine GIP obtained from J. C. Brown, Vancouver. A fresh standard curve was prepared for each assay. The radioimmunoassay was carried out as follows: $30 \mu \mathrm{l}$ of plasma $+270 \mu \mathrm{l}$ of phosphate buffer containing $6 \%$ albumin or $200 \mu \mathrm{l}$ standard GIP solution in $6 \%$ albumin buffer (from 0 to $1000 \mathrm{pg} / \mathrm{ml}$ ) were incubated for $24 \mathrm{~h}$ with $200 \mu \mathrm{l}$ of $\mathrm{R} 65$ diluted 1:5000. $200 \mu \mathrm{l}$ ${ }^{125}$ I-labelled GIP (specific activity approximately $100 \mu \mathrm{Ci} / \mu \mathrm{g}$, concentration $400 \mathrm{pg} / \mathrm{ml}$ ) were added and the incubation continued for a further $24 \mathrm{~h}$. The free and antibody bound ${ }^{125}$ I-labelled GIP were separated by addition of $1.8 \mathrm{ml}$ alcohol, followed by centrifugation. The alcohol supernatant - representing the free ${ }^{125}$ I-labelled GIP - was decanted into clean tubes and the ${ }^{125} \mathrm{I}$ counted.

The minimum detectable standard was $25 \mathrm{pg} / \mathrm{ml}$ (or $5 \mathrm{pg} /$ tube). No cross reactivity (immuno GIP less than $100 \mathrm{pg} / \mu \mathrm{g}$ ) was found with natural porcine 

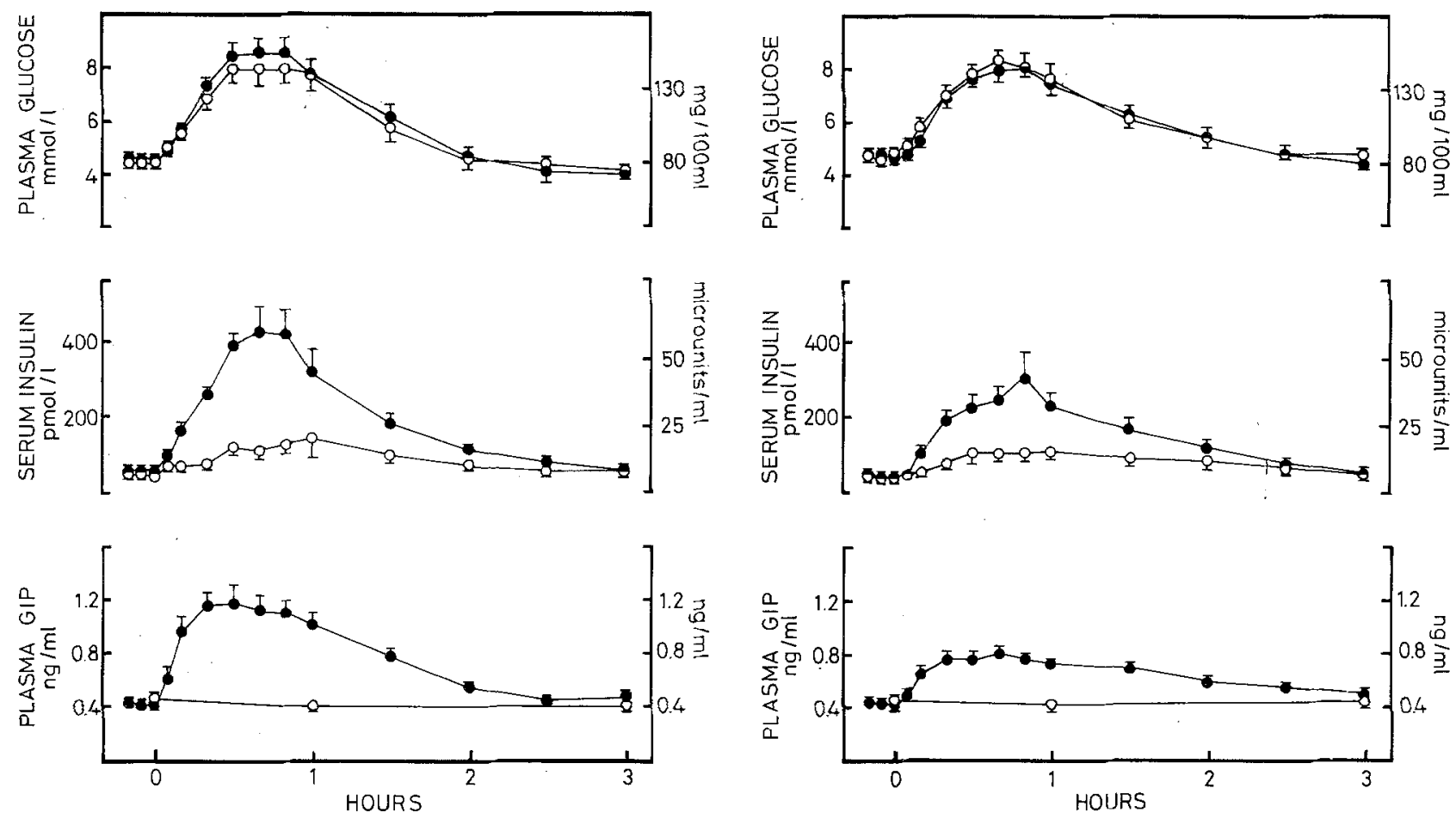

Fig. 1. Plasma glucose, serum insulin and plasma Gastric Inhibitory Polypeptide concentrations during an oral glucose tolerance test $(\longrightarrow)$ and an intravenous glucose infusion $(\mathrm{O}-\mathrm{O})$ in ten duodenal ulcer patients. The concentrations are shown as mean \pm SEM

Fig. 2. Plasma glucose, serum insulin and plasma Gastric Inhibitory Polypeptide concentrations during an oral glucose tolerance test (- and an intravenous glucose infusion $(\mathrm{O}-\mathrm{O})$ in ten healthy controls. The concentrations are shown as mean \pm SEM

VIP and secretin, donated by V. Mutt, glucagon (Novo) and porcine gut GLI [13]. A single batch of purified PCCK donated by V. Mutt contained $2 \mathrm{ng}$ GIP/ $\mu \mathrm{g}$. Gel filtration of post-absorptive plasma separated the plasma IR-GIP into a small amount eluting in the void volume of Sephadex-G 50, a main peak which eluted in the same position as ${ }^{125}$ I-GIP and porcine GIP added to human plasma and some minor fractions eluting behind the main peak.

Repeated assays of a fasted and a post oral glucose plasma gave values of $296 \pm 114$ and $1080 \pm 267 \mathrm{pg} / \mathrm{ml}$, respectively (mean $\pm \mathrm{SD}$, $\mathrm{n}=19$ ). Serial dilutions (from $1: 2$ to $1: 20$ ) of 10 plasma with high endogenous GIP were superimposable on the standard curves.

\section{d. Calculations}

The values presented are means \pm SEM. The significance of differences between two sample means was estimated by the $t$-test. P-values less than 0.05 were considered significant. The incretin effect was calculated from the following formula [14]: Incremental insulin area at OGTT - incremental insulin area at IVGI/incremental insulin area at IVGI. The

fasting insulin concentration was used as baseline for the integration from 0 to $180 \mathrm{~min}$. Plasma GIP in the fasting state was used as baseline for the calculation of integrated GIP response from 0 to $180 \mathrm{~min}$.

\section{Results}

Matching of oral and intravenous glucose concentration curves:

It was possible to match the IVGI plasma glucose to the OGTT plasma glucose in the control subjects and in the patients (Figs. 1 and 2). The controls received $20 \pm 2 \mathrm{~g}$ glucose and the patients $25 \pm 3 \mathrm{~g}$ glucose during the IVGI to match the OGTT. This difference was not statistically significant.

\section{Plasma Glucose Concentrations}

None of the subjects had a diabetic oral glucose tolerance although one of the patients (no. 9) had a borderline glucose tolerance ( 60 plus 120 min sum plasma glucose: $17.7 \mathrm{mmol} / \mathrm{l})$. Mean glucose concentrations in the fasting state were identical in patients and controls. No significant difference in 
mean integrated glucose response or in mean glucose concentrations was found between patients and controls, although mean glucose response to OGTT was slightly higher in the patients.

\section{Serum Insulin Concentrations}

The rise in serum insulin concentrations during OGTT was steeper in patients than in controls. In the time interval 5-40 min inclusive the mean insulin concentrations and the mean maximal insulin concentration were higher in the patients. The insulin response to IVGI was identical in patients and controls, $0.91 \pm 0.26 \mathrm{mU} / \mathrm{ml} \times 180 \mathrm{~min}$ and 0.97 $\pm 0.29 \mathrm{mU} / \mathrm{ml} \times 180 \mathrm{~min}$ respectively. The incretin effect in patients was $4.9 \pm 1.0$, non-significantly higher than in controls: $3.0 \pm 1.0$.

\section{Plasma GIP Concentrations}

Peak GIP concentrations preceded peak insulin concentrations in each individual in both groups. Mean GIP concentrations were significantly elevated in the patients in the time interval 10-60 min inclusive. The integrated GIP response was $63.4 \pm 11.1 \mathrm{ng} / \mathrm{ml}$ $\times 180 \mathrm{~min}$ in the patients, significantly higher than in the controls: $38.4 \pm 6.9 \mathrm{ng} / \mathrm{ml} \times 180 \mathrm{~min}$. There was a significant positive correlation $(\mathrm{r}=0.81$, $\mathrm{p}<0.01$ ) between integrated GIP response and integrated glucose response to OGTT in the patients (see Table 1), but not in the controls.

\section{Gastric Secretory Function}

No correlation was found between BAO and PAO and integrated GIP response to OGTT in the patients.

\section{Discussion}

The duodenal ulcer patients described here had normal insulin responses to intravenous glucose, in agreement with the findings of Buchanan et al. [15] and Miyoshi et al. [16]. In all subjects the insulin levels were higher after the oral glucose load than after the intravenous glucose infusion which mimicked the oral glucose tolerance curve. There was a marked increase in plasma GIP after the oral glucose load but not after the intravenous glucose load. This finding confirmed previous observations obtained by others, using a different anti-GIP serum, that oral glucose releases GIP [2]. The concept that GIP is an incretin [17] is supported by this stimulation of GIP release by oral glucose, and by the finding that the GIP and insulin responses to oral glucose were higher in patients with duodenal ulcer than in the controls.

GIP response to a mixed meal [18] and to a test meal [19] is greater in patients with duodenal ulcer disease. These findings, together with the demonstration that the GIP response to oral glucose is normal or elevated, rule out the possibility that GIP hyposecretion is a causal factor of duodenal ulcer disease. Arnold et al. [19] found that the degree of GIP response to a test meal containing $100 \mathrm{~g}$ glucose depended on the glucose response to the meal. In the present study there was a positive linear correlation between the GIP response and the glucose response to the oral load in duodenal ulcer patients. Examination of the data of the individual patients (Table 1) revealed that it was possible to divide the group into two: one with an integrated glucose response of $<300 \mathrm{mmol} / 1 \times 180 \mathrm{~min}$ (which was close to that of the controls) and a second group with a response $>300 \mathrm{mmol} / 1 \times 180 \mathrm{~min}$. This arbitrary division gave group means for the GIP response of 39 and $100 \mathrm{ng} / \mathrm{ml} \times 180 \mathrm{~min}$ respectively compared to a mean for the control group of 38 . The average age of the two groups was different - 36 and 55 years respectively - but the high mean age of the second group was influenced by one 71 year old patient. It can therefore be concluded that, as in Arnold's report [19], duodenal ulcer patients may be classified as either high or normal glucose responders to oral glucose or a test meal. All of the patients reported by Arnold et al. [19] had an increased glucose response to the test meal, whereas most of the patients reported in the present study had a normal response to the oral glucose load. This difference could be due to a difference in patient material, or by our use of a small $(50 \mathrm{~g})$ oral glucose load, which was not large enough to expose the 'glucose intolerance' found by Arnold et al. [19]. Miyoshi et al. [16] have also found, using a $50 \mathrm{~g}$ load, that duodenal ulcer patients had normal glucose tolerance, whereas Humphrey et al. [20] reported that $40 \%$ of duodenal ulcer patients had reduced tolerance to an $88 \mathrm{~g}$ oral glucose load.

The cause of the increased glucose and GIP response to an oral load of carbohydrate is not known. It is unlikely that it is caused by a reduction in glucose disposal because tolerance to intravenous glucose is normal in duodenal ulcer patients $[15,16]$. The likely cause of the high glucose and GIP response is therefore an increased glucose absorption, which may be the result of the more rapid gastric emptying known to occur in duodenal ulcer patients [21].

It is concluded on the basis of the present work 
and that of Arnold et al. [19] and Cataland et al. [18] that duodenal ulcer patients have an increased GIP and glucose response to oral glucose. The degree of increase is dependent on the size of the load. The duodenal ulcer patients can probably be divided into two groups on the basis of their response to an oral load rich in carbohydrates: those with a slightly elevated glucose and GIP response and those with a markedly elevated glucose and GIP response. The clinical significance of this division remains to be established.

Acknowledgements. The technical assistance of Annegrete Pedersen, Esther Gammelgaard Mortensen and Käthe Christensen is gratefully acknowledged.

This work was supported in part by a grant from Løvens Kemiske Fabrik.

\section{References}

1. Polak, J.M., Bloom, S. R., Kuzio, M., Brown, J. C., Pearse, A.G.E.: Cellular localization of gastric inhibitory polypeptide in the duodenum and jejunum. Gut 14, 284-288 (1973)

2. Cataland, S., Crockett, S.E., Mazzaferri, E.L.: Gastric inhibitory polypeptide (GIP) stimulation by oral glucose in man. J. Clin. Endocrinol. Metab. 39, 223-228 (1974)

3. Thomas, F.B., Shook, D.F., O'Dorisio, T.M., Cataland, S., Mekhjian, H.S., Caldwell, J.H., Mazzaferri, E. L.: Localization of gastric inhibitory polypeptide release by intestinal glucose perfusion in man. Gastroenterology 72, 49-54 (1977)

4. Thomas, F.B., Mazzaferri, E. L., Crockett, S.E., Mekhiian, H. S., Gruemer, H. D., Cataland, S.: Stimulation of secretion of gastric inhibitory polypeptide and insulin by intraduodenal amino acid perfusion. Gastroenterology 70, 523-527 (1976)

5. Pederson, R.A., Schubert, H.E., Brown, J. C.: Gastric inhibitory polypeptide. Its physiologic release and insulinotropic action in the dog. Diabetes 24, 1050-1056 (1975)

6. Falko, J.M., Crockett, S. E., Cataland, S., Mazzaferri, E. L.: Gastric inhibitory polypeptide (GIP) stimulated by fat ingestion in man. J. Clin. Endocrinol. Metab. 41, 260-265 (1975)

7. Pederson, R. A., Brown, J. C.: Inhibition of histamin-, pentagastrin-, and insulin-stimulated canine gastric secretion by pure 'gastric inhibitory polypeptide'. Gastroenterology $\mathbf{3}$, 393-400 (1972)

8. Pederson, R. A., Schubert, H.E., Brown, J.C.: The insulinotropic action of gastric inhibitory polypeptide. Can. J. Physiol. Pharmacol. 53, 217-223 (1975)

9. Natvig, H.: Nye høyde-vekttabeller for norske kvinner og menn. Oslo: Landsforeningen for kosthold og helse 1956
10. Scherstèn, H. S., Kühl, C., Hollender, A., Ekman, R.: Blood glucose measurement with Dextrostix and new reflectance meter. Br. Med. J. 1974 III, 384-387

11. Kay, A.W.: Effect of large doses of histamine on gastric secretion of $\mathrm{HCl}$. An augmented histamine test. Lancet $1953 \mathrm{I}$, $77-82$

12. Moody, A.J., Lauritsen, K. B.: A sensitive radio-immunoassay for plasma GIP. (Abstract) Gastrointestinal hormones and pathology of the digestive system. V. Speranza, N. Basso, E. Lezoche (Eds.). Rome: 1977

13. Sundby, F., Jacobsen, H., Moody, A.J.: Purification and characterization of a protein from porcine gut with glucagonlike immunoreactivity. Horm. Metab. Res. 8, 366-371 (1976)

14. Lindkær Jensen, S., Nielsen, O. V., Kühl, C.: The enteral insulin-stimulation after pancreas transplantation in the pig. Diabetologia 12, 617-620 (1976)

15. Buchanan, K.D., McKiddie, M. T., Lindsay, A.C., Manderson, W. G.: Carbohydrate metabolism in duodenal ulcer patients. Gut 8, 325-331 (1967)

16. Miyoshi, A., Ohe, K., Okuhara, S., Okayama, T., Kobayashi, K., Masumi, M., Ishida, K.: The impaired insulin release in response to oral glucose in patients with gastric ulcer. Hiroshima J. Med. Sci. 25, 191-198 (1976)

17. Grossman, M. I., et al.: Candidate hormones of the gut. Gastroenterology 67, 730-755 (1974)

18. Cataland, S., O’Dorisio, T.M., Brooks, R., Mekhjian, H.S.: Stimulation of gastric inhibitory polypeptide in normal and duodenal ulcer patients. Gastroenterology 73, 19-22 (1977)

19. Arnold, R., Ebert, R., Becker, H.D., Börger, H.W., Schafmayer, A., Creutzfeldt, W.: Serum gastric inhibitory polypeptide (GIP) response in patients with duodenal ulcer, dependence on glucose tolerance. Abstract. First International Symposium on Hormonal Receptors in Digestive Tract Physiology. INSERM Symposium No 3. S. Bonfils, P. Fromageot, G. Rosselin (Eds.) 509-510. Elsevier/North-Holland: Biomedical Press 1977

20. Humphrey, C.S., Dykes, J.R.W., Johnston, D.: Glucose tolerance and insulin secretion in patients with chronic duodenal ulcer. Br. Med. J. 1972 IV, 393-396

21. Griffith, G.H., Owen, G. M., Campbell, H., Shields, R.: Gastric emptying in health and in gastroduodenal disease. Gastroenterology 54, 1-7 (1968)

Received: June 3, 1977,

and in revised form: September 23, 1977

K. B. Lauritsen, M.D.

Department of Surgical Gastroenterology

Afsn. 235

Hvidovre Hospital

DK-2650 Hvidovre

Denmark 